\title{
Covid-19 in mind: how job loss and health threatening events modulate risk-taking behaviours in real-life contexts
}

Authors: Caterina Galandra ${ }^{1}$, Chiara Cerami ${ }^{2,3^{*}}$, Gaia Chiara Santi ${ }^{2}$, Alessandra Dodich ${ }^{4}$, Stefano F. Cappa ${ }^{2,3}$, Tomaso Vecchi ${ }^{3,5}$, Chiara Crespi ${ }^{5}$

\section{Affiliations:}

1. Istituti Clinici Scientifici Maugeri IRCCS, 27100, Pavia, Italy

2. NEtS center, Scuola Universitaria Superiore IUSS Pavia, 27100, Pavia, Italy

3. IRCCS Mondino Foundation, 27100, Pavia, Italy

4. Center for Neurocognitive Rehabilitation, $\mathrm{CIMeC}$, University of Trento, Italy

5. Department of Brain and Behavioral Sciences, University of Pavia, 27100, Pavia, Italy

${ }^{*}$ Corresponding author

Dr. Chiara Cerami, MD

Scuola Universitaria di Studi Superiori IUSS-Pavia

Street address: Piazza della Vittoria, 15, 27100 Pavia, Italy

E-mail address: chiara.cerami@iusspavia.it 


\section{ABSTRACT}

Covid-19 pandemic is exerting a tragic impact all around the world. Firstperson experience of life-threatening and stressful events can modify individuals' risk perception, and, consequently, risk-taking behaviours.

Here we investigated risk-taking profiles in 130 Italian residents, and compared healthcare to non-healthcare workers, during the lockdown phase. We ad hoc developed the "Covid-19 Risk Task", including the classic monetary Holt-Laury Paired Lottery Task (Monetary Condition, MC) and two new ecological conditions exploring Covid-19 related risk-taking aptitudes in relation

to different health (Health Status Condition, $\mathrm{HsC}$ ) and employment (Employment Status Condition, EsC) outcomes.

Results showed that, in the whole sample, individuals were more risk-averse in $\mathrm{MC}$ than in $\mathrm{HsC}$ and $\mathrm{EsC}$. Moreover, a payoff increase produced a shift toward more risk-averse behaviours in $\mathrm{MC}$, but not in $\mathrm{HsC}$ and $\mathrm{EsC}$, where we found an opposite trend suggesting a more risk-loving behaviour. Finally, we found that healthcare workers were significantly less risk-averse compared to non-healthcare workers in $\mathrm{EsC}$, but not in $\mathrm{MC}$ and $\mathrm{HsC}$.

These findings provided evidence of the possible effects of Covid-19 outbreak on risk-taking aptitudes. The negative impact on human choices and, consequently, on the whole world economy of this catastrophic life event must not be underestimated. 
Keywords: Covid-19; risk-taking; risk aversion; healthcare workers; health; economy; ecological task 


\section{Introduction}

Covid-19 pandemic has triggered in a few weeks a global health emergency and a social and economic crisis as never seen before. As the outbreak increased worldwide, forced measures of social distancing and isolation were progressively adopted by national governments. In Italy, the abrupt wave of infected cases recorded in Northern regions imposed extreme containment measures and social distancing from March to May 2020. In the meanwhile, there has been a complete reorganization of healthcare activities of public and private institutions in order to take charge of the high number of Covid-19 positive patients and to contain the spread of the epidemic, especially in Northern Italy.

Since the Italian government decree of March 9, 2020 (DCPM \#iorestoacasa - I stay at home) imposed a lockdown all over the country, millions of people changed work habits, daily routines and lifestyles. Only a few industries, and small and large traders were kept open (i.e. manufacturers of essential goods or healthcare providers), while many workers have been signed for a temporary layoff, and in some cases dismissed. Freelance workers became suddenly unemployed. Millions of jobs are now at risk.

The huge number of deaths - i.e. 32.330 people at the time of writing (May 20,2020 ) - that hit thousands of families, the dramatic economic consequences of the lockdown on job market (i.e. $\sim+15 \%$ of unemployed workers, job seekers or non-workers and $\sim-5 \%$ of Gross Domestic Product on the first quarter of 
2020; https://www.istat.it/it/archivio/lavoro), and the decrease of people's psychosocial well-being has exposed millions of Italian citizens to a large-scale catastrophic event, within a very short amount of time.

Data collected after large-scale catastrophic events as natural disasters (e.g., tsunami [1] or earthquake [2]) or wars [3] proved that the first-person experience of extremely life-threatening and stressful events may change individuals' perception of risk and consequently modulate their risk-taking aptitude. Literature findings are, however, controversial about the direction of such a change. In some cases, the experience of extremely stressful catastrophe leads people to increase their risk perception, and thus they became more riskaverse. Risk-averse individuals typically prefer a sure outcome over a risky gamble, even in case of a higher expected value [1-3]. Such an aptitude would keep the risk-averse subject safe from the experience of unpleasant feelings and negative emotions possibly emerging from an undesired outcome [4]. For instance, Cassar and colleagues [1] showed that tsunami survivors were more risk-averse compared to subjects not directly involved in the catastrophic event. Despite the fact that only a few respondents declared that someone of their relatives was physically assaulted $(3.7 \%)$ or had property stolen $(5.8 \%)$ or burned $(2.1 \%)$ during the civil protests, Jakiela and Ozier reported similar results in Kenyan young citizens after post-election crisis [5].

Conversely, other studies reported that the exposure to catastrophic events may produce a shift of the individual risk-taking profile toward a more risk-prone aptitude. In this case, risk-loving individuals prefer a more uncertain option over 
another with an equal but less risky expected outcome $[3,6]$. Indeed, using a classical monetary task Eckel and colleagues [6] investigated individuals risk aptitude immediately after hurricane Katrina in New Orleans. They found that exposed subjects were on average more prone towards risk compared to a demographically matched group of Huston's citizens not exposed to such a catastrophic event. A similar risk-proneness was observed in people gone through indiscriminate violence during civil-war between the two main ethnic group of Burundi [3].

Taken together, all these findings confirm the idea that people who experienced first-person life-threatened catastrophic situations may undergo a significant change in their risk-taking aptitudes. They may thus become more risk-averse, as they experienced situations of extreme danger for their own lives and feel themselves as miracle survivors, or more risk-lovers, as they consider themselves immune to such danger.

No catastrophic event previously offered the opportunity to investigate changes in risk aptitudes directly during a large-scale long-lasting catastrophe. For this reason, Covid-19 outbreak is a unique opportunity for research. To the best of our knowledge, previous studies investigating risk-taking attitudes and behaviours in people who experienced catastrophic events typically used tasks with monetary stimuli and collected the data after the occurrence of such events, focusing on its long-term consequences. Moreover, the impact of catastrophic events on risk-taking aptitudes in relation to more ecological stimuli, including the possibility of falling ill or to suddenly change the 
employment status (e.g., layoffs, reductions in the working time), is still unexplored.

Taking into account the multifaceted consequences of the Covid-19 outbreak in Italy - including the sanitary emergency and its impact on psychosocial wellbeing, as well as the economic and job crisis - we developed a new task for risk-taking assessment (i.e. the Cov19 Risk Task, Cov19-RT), by adding two new ecological experimental conditions to the Holt-Laury Paired Lottery Task, a classical decision-making task based on a multiple price list (MPL) design including monetary stimuli [7]. Thus, the Cov19-RT includes a Monetary Condition (Cov19-RT MC) and two conditions specifically designed to explore the individual risk-taking aptitudes in relation to different Covid-19 related health (Health Status Condition, Cov19-RT HsC) and employment (Employment Status Condition, Cov19-RT EsC) outcomes.

Our primary aim was thus to describe risk-taking profiles in Italian residents during the lockdown phase and record how the experience of Covid-19 pandemic may affect individuals' risk-taking attitudes in the general population, by comparing the monetary condition to the new ecological ones. Then, we tested the presence of the so-called incentive effect (a general shift to the safe option due to a payoff increase, see [7]) in all the conditions. Finally, in view of our previous report [8; preprint, doi:10.31234/osf.io/z7yuv], which highlighted that healthcare workers perceived the Covid-19 emergency for health as more severe compared to non-healthcare workers, we investigated group differences on the basis of participants' work status as well. 
In the current context, we expected that the ecological conditions related to health and employment outcomes - and specifically tailored on the Covid-19 pandemic - may provide a different, and possibly more realistic, description of risk-taking behaviours during a catastrophic event in comparison to the classical monetary condition. In particular, we hypothesized that Italians would be more averse toward risk in the monetary condition than in the health and employment ones. Finally, we expected that healthcare workers, who maintained their job occupation and salary during the Covid-19 pandemic, would be less risk averse in relation to the employment-related outcomes compared to non-healthcare workers.

\section{Results}

\subsection{Demographic information and risk-taking profiles}

Descriptive statistics of demographic information and risk-taking profiles are reported in Tables 1-2 and Figure 1.

\subsection{Relationship between monetary and new ecological conditions}

In the whole sample, we found a significant relationship between the two new ecological conditions ( $\mathrm{mHsC}$ and mEsC: Spearman's $r=-0.231, p<0.008)$ but no significant relationship between the classical monetary condition and the new Covid-19 related conditions ( $\mathrm{mHsC}$ and $\mathrm{mMC}$ : Spearman's $r=0.47, p=0.592$; mEsC and mMC: Spearman's $r=0.49, p=0.578)$. Moreover, Freedman test on 
$\mathrm{mMC}, \mathrm{mHsC}$ and $\mathrm{mEsC}$ highlighted significant differences in risk-taking behaviours between the three task conditions $\left(\chi^{2}=76.177, p<0.0001\right)$. Post hoc analysis (Wilcoxon signed-ranks test) revealed that subjects were significantly more risk-averse in $\mathrm{mMC}$ compared to both $\mathrm{mHsC}(z=-7.919, p<0.0001$, effectsize: $r=0.895)$ and $\mathrm{mEsC}(z=-3.002, p<0.003$, effect-size: $r=0.344)$, and in $\mathrm{mEsC}$ compared to $\mathrm{mHsC}(\mathrm{z}=-5.872, p<0.0001$, effect-size: $r=-0.663)$.

\subsection{Incentive Effect}

In order to test the presence of the incentive effect (i.e., a general shift to the safe option due to a payoff increase) we assessed a within-group comparison (Wilcoxon signed-rank test) on risk-taking profiles of Series 1 (lower payoffs) and Series 2 (higher payoffs). Wilcoxon signed-ranks test on Cov19-RT MC in the whole sample highlighted that a payoff increase from Series 1 to Series 2 produced a significant shift toward more risk-averse behaviours $(z=-3.343$, $p<0.001$, effect-size: $r=-0.532$ ). In Cov19-RT HsC and EsC conditions we found the opposite trend, and the payoff increase produced a significant shift toward more risk-loving behaviours (HsC: $z=-7.780, p<0.001$, effect-size: $r=0.905$; EsC: $z=-8.585, p<0.001$, effect-size: $r=0.921$ ) (Table 3A; Figure 2).

When we considered the healthcare and non-healthcare workers separately, we found that both groups displayed the incentive effect in $\mathrm{HsC}$ (healthcare workers: $z=-5.477, p<0.001$, effect-size: $r=0.907$; non-healthcare workers: $z=-$ 5.666, $p<0.001$, effect-size: $r=0.898$ ) and EsC (healthcare workers: $z=-6.042$, $p<0.001$, effect-size: $r=0.910$; non-healthcare workers: $z=-6.139, p<0.001$, 
effect-size: $r=0.932$ ), but only non-healthcare workers showed a significant payoff effect in $M C(z=-3.699 ; p<0.001$, effect-size: $r=-0.830)$ (Table 3A).

\subsection{Risk-taking aptitudes in healthcare vs. non-healthcare workers}

Between-group analysis (Mann-Whitney test) comparing healthcare and nonhealthcare workers on risk-taking aptitude profiles highlighted significant differences in $\mathrm{EsC}$ measures $(\mathrm{EsC} 1: \mathrm{U}=1562, p<0.0001$, effect-size: $r=0.261$; EsC2: $U=1704, p<0.040$, effect-size: $r=0.193$; mEsC: $U=1517.5, p<0.003$, effectsize: $r=0.282$ ), showing that healthcare workers are significantly less risk-averse compared to non-healthcare workers (Table 3B). We did not found significant group differences in $\mathrm{MC}(\mathrm{MC1}$ : $U=1880, p<0.242$, effect-size: $r=-0.110 ; \mathrm{MC2}$ : $U=2022.5, p<0.626$, effect-size: $r=0.043 ; m M C: U=2080.5, p<0.870$, effect-size: $r=-0.015)$ and $\mathrm{HsC}(\mathrm{HsC1}: \mathrm{U}=1943, p<0.401$, effect-size: $r=-0.080 ; \mathrm{HsC2}$ : $U=1993.5, p<0.434$, effect-size: $r=-0.056$; $m$ HsC: $U=1795, p<0.108$, effect-size: $r=-0.150)$ measures. See Table 3B.

\section{Discussion}

Italy was the first Western country to be severely affected by the SARS-CoV2 virus. The way Italian people are reacting to this life-threatening event, as well as to the severe restrictions imposed on work activities, likely reflects the disruptive changes that the Covid-19 outbreak, first, and the lockdown measures, later, have exerted on health and economic outcomes in Italy. 
In this study, we explored real-life behaviours in the days of the Covid-19 outbreak trying to expand current literature about individual risk-taking aptitudes and following behaviours in relation to the experience of catastrophic events that may put life in danger and jobs at risk. We also aimed to provide useful insights to orient healthcare and economy strategies in the very next future and in case of novel pandemic.

As the Covid-19 lockdown measures were put in place, the first impulse was to make a historical parallel. However, as the weeks went by, the singularity of the shock we are going through became clear. The numbers of deaths seen over such a short time, and the current implosion of the world economy concentrated within a few months, make this pandemic an exceptional event. Literature suggests that the first-person experience of extremely life-threatening and stressful events usually can lead people to increase their risk perception, pushing individuals to became more risk-averse [1,5]. However, there is also opposite evidence reporting that catastrophe survivors display more risk-loving aptitude $[3,6]$. These opposite profiles in risk-taking aptitudes after the experience of life-threatening events have been inferred from experimental settings using risk tasks with monetary lotteries. Moreover, these tasks have been administered to survivors only after the catastrophic events $[1,3,5-6]$. In the light of these considerations, it is likely that both the late timing of data collection and the use of paradigms including exclusively monetary stimuli which might be not suitable enough to capture real-life changes - somewhat biased previous inferences on risk aptitude profiles of survivors from 
catastrophic events. The use of more ecological stimuli, as those developed for this study, together with a well-timed data collection during the emergency period, can possibly overcome such limitations.

Our data showed that, overall, individuals displayed more risk-averse behaviours in the monetary condition than in the novel ecological ones. Notably, while individual patterns observed in the two ecological conditions were significantly correlated, we did not find significant association with risk-taking profiles emerging from the classic monetary condition. This evidence suggests that the individual variability in risk-taking profiles emerging from the monetary condition is totally independent from that resulting from the Covid-19-related conditions. These two latter, exploring individuals' risk-taking aptitudes in two very different domains, namely the health and employment status , are tightly and negatively linked to each other. Notably, the negative direction of the relationship between the two ecological conditions might be explained in terms of a preferential allocation of attentional resources to the most relevant domain for the individual during the Covid-19 outbreak. To this purpose, we could speculate that people who are more worried about possible long-term economic consequences, as a result of changes possibly occurring in their employment condition, would display a more risk-averse aptitude in the $\mathrm{EsC}$ rather than in the $\mathrm{HsC}$, as they are possibly more willing to undertake the risk to fall ill rather than the risk to experiment aversive economic consequences due to the detrimental impact of Covid-19 outbreak on job market and productive activities. On the contrary, this evidence might suggest that who is more concerned about 
possible negative health outcomes related to the Covid-19 outbreak, would then show a more risk-averse aptitude in the $\mathrm{HsC}$ rather than in the $\mathrm{EsC}$, as the worry about health overcomes that of losing a regular income, or also because Covid-19 emergency did not affect their job occupation.

Moreover, in line with the literature [7], we observed the presence of a significant incentive effect in MC, with a shift toward more risk-averse behaviours as the payoff increased. As expected, Italians inhabitants, who are actually experiencing such an unpredictable life situation, possibly afflicting each kind of people's certainties, preferred a sure monetary outcome over a risky gamble. A risk-averse aptitude may, indeed, work as a self-protection strategy, keeping people safe from the experience of unpleasant feelings and negative emotions possibly emerging from an undesired but possible negative monetary outcome.

At the opposite, we observed a reversed incentive effect by comparing Series 1 and Series 2 payoffs in $\mathrm{HsC}$ and $\mathrm{EsC}$. Indeed, in both these conditions, we found a shift toward more risk-loving behaviours as the payoff increased. This evidence may be explained by the specific nature of the ecological lotteries, which allow people to precisely anchor each stimulus to possible health and employment consequences related to the Covid-19 emergency, and thus resulting particularly salient for the self, compared to more abstract monetary stimuli. Indeed, since these stimuli encase real outcomes defining individuals' health and socio-economical and, ultimately, personal status, risk-loving behaviours might be due to the attempt to reach the most favourable condition 
and/or to avoid the most potentially threatening ones. Moreover, by including prevalently young adults (mean age $=38$ y.o.; median $=37$ y.o.), it is possible that such a reversed incentive effect may reflect the fact that they consider themselves in an advantageous condition, having a great number of opportunities for their personal life and, thus, willing to risk in order to obtain the best outcome possible. Moreover, younger people have been proved to have more risk-prone aptitudes than older people [9].

Overall, our results on the incentive effect in MC condition confirmed Holt and Laury [7] findings, highlighting that scaling up the payoff in hypothetical monetary lotteries (i.e. without a real winning) makes little differences in risktaking aptitudes. Conversely, using ecological stimuli specifically related to the current emergency situation has the same effect as real monetary lotteries (i.e. with a real winning [7]) provoking a greater shift in risk-taking aptitudes, as proved by a larger effect size in $\mathrm{HsC}$ and $\mathrm{EsC}$ compared to $\mathrm{MC}$ (see Figure 2). Thus, it seems that Covid-19 related ecological stimuli, because of their intrinsic features triggering real-life experiences, are able to elicit more realistic riskrelated behaviours.

Finally, we found that healthcare workers were significantly less risk-averse compared to non-healthcare workers in the $\mathrm{EsC}$ conditions, but not in the $\mathrm{MC}$ and $\mathrm{HsC}$ conditions. This finding may reflect the overall stability of healthcare workers' employment status, differently from other workers whose occupation was actually at risk or unpredictable, due to the lockdown measures. Indeed, the unemployment rate - which was at an all-time low even in countries like the 
United States - is exponentially growing now. Western economies have been hit by an unprecedented shock wave. Economic cycles usually start from the most unstable sectors (such as real estate or construction) or from the most exposed to global competitors (e.g. automotive industry). This time, however, the lockdown also affected retail services, education, the entertainment industry, as well as restaurants, tourism and travel sectors. All these activities employ the majority of a country's population. For this reason, the catastrophic effect has been immediate, and millions of jobs will be possibly permanently lost. Such a negative view influence individuals' risk perception, likely prompting more riskaverse aptitudes in approaching disruptive consequences affecting the working world.

A major limitation of the present study is represented by the cross-sectional nature of the report, which prevents to draw causal conclusions on longitudinal changes of individual risk-taking aptitudes. Moreover, the small-to-moderate sample size may hinder the generalization of present results to the general population. Only future replication studies using both monetary and ecological conditions on larger samples can confirm the reliability of the present results.

In conclusion, we provided evidence that experiencing the psychosocial consequences of Covid-19 outbreak can modulate individual risk-taking profiles in real-life situations. The tragic negative effects of this catastrophic life event, threatening health and occupation must not be underestimated.

\section{Methods}




\subsection{Sample size}

We carried out an 'a priori' power analysis on the risk aptitude difference between the three conditions of the Covid-19 Risk Task (Cov-19 RT). We used G*Power (https://g-power.apponic.com/) and found that a sample size of 128 subjects provides a statistical power of 0.95 in identifying a significant difference, performing a Wilcoxon signed-ranks test (matched pairs) with effect size $d z=0.3$ and statistical significance of 0.05 .

\subsection{Participants}

Immediately after the lockdown phase disposed by Italian government on March 9, 2020 (DCPM \#iorestoacasa - I stay at home), we launched the PsyCOVID study aiming at evaluating changes in lifestyles, habits, routines and psychosocial dimensions in the Italian population during the social distancing period (see baseline findings at [8], DOI: 10.31234/osf.io/z7yuv). Between April 3 and 23, 2020, we collected data on 65 healthcare workers (females: 83.1\%; mean age: $38.43 \pm 10.37$ yo; age range: $25-64$ yo; mean years of education: $17.51 \pm 1.11$ yy; education range: $13-18$ yy) and a well-matched group of 65 nonhealthcare workers (females: $53.8 \%$; mean age: $38.46 \pm 8.18$ y.o.; age range: $25-$ 64 y.o.; mean years of education: $17.11 \pm 1.7$ yy; education range: $13-18$ yy), selected by convenience among PsyCOVID study participants [8; preprint, doi:10.31234/osf.io/z7yuv]. We enrolled only Italian residents with age between 25 and 64 years in order to consider people within the working age. Among non- 
healthcare workers, we preliminary excluded PsyCOVID participants who formerly recorded themselves as unemployed, student, housewife or retired from work.

We implemented the experimental task Cov19-RT in an on-line survey with Google Forms, which we distributed by direct link, via e-mail or whatsapp to each participant. Participants provided their consent to the experimental procedure, which was approved by the IUSS-University of Pavia Ethics Committee.

Table 1 provides details about the participants' socio-demographic characteristics.

\subsection{The Covid-19 Risk Task}

In order to assess risk-taking aptitudes during Covid-19 pandemic, we created a modified version of the Holt-Laury Paired Lottery Task [7] with hypothetical monetary payoff, a task wildly used to assess risk-related behaviours after catastrophic events, such as natural disasters [10]. In the original task, composed by 10 paired monetary lotteries presented on different decision rows, participants have to make a choice between Lottery A and Lottery B (Table 4). In any decision row, Lottery A always shows the "safe" choice while Lottery B represents the "risky" choice, as Lottery A has less variability in the payoffs than Lottery $B$. The 10 decision rows differed in terms of the probability of winning the higher prize in each lottery. In the first decision row, the probability of winning the higher prize is $10 \%$, while for the subsequent 9 
decision rows, the probability to obtain the better outcome progressively increases by $10 \%$ so that by decision row 9 there is a $90 \%$ chance of winning the higher prize, and decision row 10 is a choice between two certain winnings.

A "risk-neutral" individual usually selects Lottery A for the first four choices, either A or B for choice 5 (i.e. 50\%-50\%) and then switches over Lottery B for the last four choices. Considering the utility function

$$
u(x)=x^{r-1}
$$

where $x$ represents the prize and $r$ represents the constant relative risk aversion coefficient (CRRA) [7,9], risk-neutral conditions are defined by $r=0$, while risk-loving and risk-averse conditions by, respectively, $r>0$ and $r<0$. In the present work, we characterized the individual risk-taking profile on the basis of Albert's $r$ cut-offs [9]. We considered four types of risk-taking profiles. identifying participants' as "risk-loving" ( $r<-0.15,0-3$ safe choices), "risk-neutral" $(-0.15<r$ $>0.15,4$ safe choices), "mildly risk-averse" $(0.15<r>0.68,5-6$ safe choices $)$ and "highly risk-averse" ( $r>0.68,7$ or more safe choices).

In addition to the classic monetary condition of Holt-Laury Paired Lottery Task (i.e. Cov19-RT MC), the Cov19-RT included two novel ecological Covid-19 related conditions, with lotteries entailing health- and employment-related outcomes (i.e. Cov19-RT HsC and EsC). Each condition (i.e. MC, HsC and EsC) included two Series of 10 paired lotteries with different payoff amounts (i.e. 
Series 1 lower payoffs and Series 2 higher payoffs) with the aim of investigating if different payoff amounts could elicit different risk behaviours.

Cov19-RT HsC and EsC were developed with the same design as MC, including paired lotteries of pathological conditions and employment status reflecting outcomes possibly occurring during the lockdown imposed by the Covid-19 emergency as choice alternatives.

First, we created two lists of 24 items (i.e. pathological conditions and employment status) (see Supplementary Table S1 and S2 for item lists) and we asked 38 healthy subjects, balanced for gender and age groups (i.e. 20-70 yo), to assess content validity of the novel experimental conditions. First, we asked subjects to assess face validity (e.g. understanding of sentences and presentation of the text). Then, to rate each item in terms of illness severity or employment hardship on a 5-point Likert scale (e.g., $0=$ Not serious at all; $1=\mathrm{Not}$ very serious; $2=$ Serious enough; $3=$ Serious; $4=$ =xtremely serious).

We than excluded unclear items and ordered the remaining items, based on overall severity perception. Finally, we designed Lottery A and Lottery B with the same CRRA coefficient of the monetary condition (i.e., health and employment conditions perceived as less severe were associated with the higher monetary values, while health and employment conditions perceived as more severe were associated with the lower monetary values), as reported in the previous paragraph.

Thus, while Cov19-RT MC includes monetary outcomes (Series 1 Lottery A: $200 €-160 €$, Lottery B: $385 €-10 €$; Series 2 Lottery A: 4.000€-3.200€, Lottery B: 
7.700€-200€), HsC entails health outcomes (Series 1 Lottery A: Symptomatic SARS-CoV2 infection without hospitalization - Type II Diabetes Mellitus, Lottery B: Shoulder Fracture - Symptomatic SARS-CoV2 infection with hospitalization; Series 2 Lottery A: Psoriasis - Asymptomatic SARS-CoV2 infection, Lottery B: Cold - Symptomatic SARS-CoV2 infection without hospitalization) and EsC employment outcomes (Series 1 Lottery A: Paid leave (salary reduced of 2/3) Work from home with $50 \%$ salary reduction, Lottery B: 30 days of paid leave Unpaid furlough; Series 2 Lottery A: 15 days of paid leave - Work with reduced work hours (part-time), Lottery B: Work from home with full salary - Paid leave (salary reduced of $2 / 3)$ ).

See Tables 4 for details on Cov19-RT stimuli.

\subsection{Statistical analyses}

We carried out statistical analyses using SPSS (https://www.spss.it/) and JASP (https://jasp-stats.org/), using non-parametric tests. We set statistical significance at $p<0.05$ for all statistical tests performed.

\subsubsection{Demographic and risk-taking aptitude variables}

We performed descriptive statistics on i) Demographic variables, reporting mean and standard deviation for pseudo-continuous measures and frequency and percentage for categorical descriptors; and ii) Risk-taking aptitudes, reporting frequency and percentage of different risk profiles (risk-loving, riskneutral, mildly risk-averse, highly risk-averse). 
For this purpose, we calculated a risk-taking measure (i.e. MC, $\mathrm{HsC}$ and EsC) for each Series (1 and 2) within each condition, using the number of safe choices (Lottery A), i.e. MC-Series 1 (MC1), MC-Series 2 (MC2), HsC-Series 1 (HsC1), HsC-Series 2 (HsC2), EsC-Series 1 (EsC1) and EsC-Series 2 (EsC2).

In addition, we computed an overall risk-taking aptitude measure for each condition (average of safe choices among the two Series), i.e., Mean MC (mMC), Mean $\mathrm{HsC}(\mathrm{mHsC})$, Mean EsC (mEsC).

The description of demographic information and risk-taking profiles are reported in Tables 1 and 2.

\subsubsection{Risk-taking behaviours}

In order to assess the overall functioning of the two new ecological Covid-19 related conditions ( $\mathrm{HsC}$ and $\mathrm{EsC}$ ) compared to the classical monetary condition (MC), we calculated the Spearman's Rank correlation coefficient among mMC, $\mathrm{mHsC}$ and $\mathrm{mEsC}$ in the whole sample.

Then, for each condition, we assessed a within-group comparison (Wilcoxon signed-rank test) on risk-taking profiles of Series 1 (lower payoffs) and Series 2 (higher payoffs) to test the presence of the incentive effect (a general shift to the safe option due to a payoff increase, see [7]). We performed this analysis in the whole group, as well as in healthcare and non-healthcare worker groups.

Moreover, we investigated within-group differences (Freedman Test and Wilcoxon post hoc analysis) in risk-taking profiles among the three conditions of the task (mMC, $\mathrm{mHsC}, \mathrm{mEsC})$. 
Finally, we explored between-group differences in risk-taking profiles in healthcare workers vs. non-healthcare workers (Mann-Whitney U Test) in each Series within each condition ( $\mathrm{MC} 1, \mathrm{MC} 2, \mathrm{HsC} 1, \mathrm{HsC} 2, \mathrm{EsC} 1, \mathrm{EsC} 2)$, as well as in global measures (mMC, $\mathrm{mHsC}, \mathrm{mEsC}$ ). For each test providing significant results we calculated effect size (Glass's rank biserial correlation test for non parametric statistics).

\section{References}

1. Cassar, A., Healy, A. \& von Kessler, C. Trust, Risk, and Time Preferences After a Natural Disaster: Experimental Evidence from Thailand. World Dev. 94, 90-105 (2017).

2. Cameron, L. \& Shah, M. Risk-Taking Behavior in the Wake of Natural Disasters. (2013).

3. Voors, M. J. et al. Violent conflict and behavior: A field experiment in Burundi. Am. Econ. Rev. 102, 941-964 (2012).

4. Kahneman, D. \& Tversky, A. Prospect Theory: An Analysis of Decision under Risk. Econometrica 47, 263-292 (1979).

5. Jakiela, P. \& Ozier, O. The impact of violence on individual risk preferences:

Evidence from a natural experiment. Rev. Econ. Stat. 101, 547-559 (2019).

6. Eckel, C. C., El-Gamal, M. A. \& Wilson, R. K. Risk loving after the storm: A Bayesian-Network study of Hurricane Katrina evacuees. J. Econ. Behav. Organ. 69, 110-124 (2009). 
7. Holt, C. A. \& Laury, S. K. Risk Aversion and Incentive Effects. American economic review. 92.5, 1644-1655 (2002).

8. Cerami, C. et al. Covid-19 Outbreak In Italy: Are we ready for the psychosocial and the economic crisis? Baseline findings from the PsyCovid Stuty. (Preprint). [cited 2020 April 13]. Available from https://doi.org/10.31234/osf.io/z7yuv.

9. Albert, S. \& Duffy. Differences in risk aversion between young and older adults. Neurosci. Neuroeconomics 2012, 3 (2012).

10. Shupp, R., Loveridge, S., Skidmore, M., Lim, J. \& Rogers, C. Risk, Loss, and Ambiguity Aversion after a Natural Disaster. Econ. Disasters Clim. Chang. 1, $121-142(2017)$. 


\section{Figure legends}

Figure 1. Risk-taking profiles for each Cov19-RT condition in the whole sample and in the healthcare workers and non-healthcare workers groups

Figure 2. Incentive effect in the three Cov19-RT conditions

\section{Acknowledgements}

We wish to thank Pigmento-LAB ETS members for their valuable contribution in subjects recruitment. We thank William Dello Russo and Bella Parlapiano for their suggestions for the graphical design of the on-line survey.

\section{Author Contributions}

CG, CCe and CCr participated in study design; CG, CCe and CCr performed data analysis and interpretation; CG, CCe and CCr drafted the main manuscript; All authors participated in data collection and reviewed the manuscript.

\section{Competing Interests Statement}

The authors declare no competing interests. 
Table 1 - Demographic variables of the sample

\begin{tabular}{|c|c|c|c|c|}
\hline & $\begin{array}{l}\text { Whole Sample } \\
\quad(n=130)\end{array}$ & $\begin{array}{l}\text { Healthcare } \\
\text { workers } \\
(n=65)\end{array}$ & $\begin{array}{c}\text { Non-healthcare } \\
\text { workers } \\
(n=65)\end{array}$ & p-value \\
\hline Female/Male \% & $68.5 / 31.5$ & $83.1 / 16.9$ & $53.8 / 46.2$ & $<0.001$ \\
\hline Age in years (mean $\pm s d)$ & $38.5 \pm 9.3$ & $38.4 \pm 10.4$ & $38.5 \pm 8.2$ & 0.985 \\
\hline Education in years (mean $\pm s d)$ & $17.3 \pm 1.4$ & $17.5 \pm 1.1$ & $17.1 \pm 1.7$ & 0.114 \\
\hline $\begin{array}{c}\text { Geographical area (Northern Italy I } \\
\text { Southern-Central Italy) \% }\end{array}$ & $73.8 / 26.2$ & $69.2 / 30.8$ & $78.5 / 21.5$ & 0.231 \\
\hline
\end{tabular}


Table 2 - Risk-taking profiles in the whole sample and in each group separately

\begin{tabular}{|c|c|c|c|c|c|}
\hline \multirow[b]{2}{*}{$\begin{array}{l}N^{\circ} \text { safe } \\
\text { choices }\end{array}$} & \multirow[b]{2}{*}{ CRRA range } & \multirow[b]{2}{*}{$\begin{array}{c}\text { Risk-taking aptitudes } \\
\text { classification }\end{array}$} & \multicolumn{3}{|c|}{ Proportion of choices } \\
\hline & & & $\begin{array}{l}\text { Whole sample } \\
\quad(n=130)\end{array}$ & $\begin{array}{l}\text { Healthcare } \\
\text { workers } \\
(n=65)\end{array}$ & $\begin{array}{c}\text { Non-Healthcare } \\
\text { workers } \\
(n=65)\end{array}$ \\
\hline \multicolumn{6}{|c|}{ Monetary Condition - mean values } \\
\hline $0-3$ & $-0.95<r>-0.15$ & Risk-loving & $8.5 \%$ & $7.7 \%$ & $9.2 \%$ \\
\hline 4 & $-0.15<r>0.15$ & Risk-neutral & $8.5 \%$ & $7.7 \%$ & $9.2 \%$ \\
\hline $5-6$ & $0.15<r>0.68$ & Mildly risk-averse & $32.3 \%$ & $33.8 \%$ & $30.8 \%$ \\
\hline $7-10$ & $r>0.68$ & Highly risk-averse & $50.8 \%$ & $50.8 \%$ & $50.8 \%$ \\
\hline \multicolumn{6}{|c|}{ Health status Condition - mean values } \\
\hline $0-3$ & $-0.95<r>-0.15$ & Risk-loving & $51.5 \%$ & $44.6 \%$ & $58.5 \%$ \\
\hline 4 & $-0.15<r>0.15$ & Risk-neutral & $14.6 \%$ & $15.4 \%$ & $13.8 \%$ \\
\hline $5-6$ & $0.15<r>0.68$ & Mildly risk-averse & $24.6 \%$ & $29.2 \%$ & $20 \%$ \\
\hline $7-10$ & $r>0.68$ & Highly risk-averse & $9.2 \%$ & $10.8 \%$ & $7.7 \%$ \\
\hline \multicolumn{6}{|c|}{ Employment status Condition - mean values } \\
\hline $0-3$ & $-0.95<r>-0.15$ & Risk-loving & $13.8 \%$ & $21.5 \%$ & $6.2 \%$ \\
\hline 4 & $-0.15<r>0.15$ & Risk-neutral & $10 \%$ & $9.2 \%$ & $10.8 \%$ \\
\hline $5-6$ & $0.15<r>0.68$ & Mildly risk-averse & $48.5 \%$ & $52.3 \%$ & $44.6 \%$ \\
\hline $7-10$ & $r>0.68$ & Highly risk-averse & $27.7 \%$ & $16.9 \%$ & $38.5 \%$ \\
\hline
\end{tabular}


Table 3 - Incentive effect and risk aptitudes

\begin{tabular}{|c|c|c|c|c|c|}
\hline \multicolumn{6}{|c|}{ A. Incentive effect } \\
\hline & $\mathbf{z}$ & \multicolumn{2}{|c|}{ p-value } & \multicolumn{2}{|c|}{$\mathbf{r}$} \\
\hline \multicolumn{6}{|l|}{ Whole sample } \\
\hline $\mathrm{mMC}$ & -3.343 & \multicolumn{2}{|c|}{0.001} & \multicolumn{2}{|c|}{-0.532} \\
\hline $\mathrm{mHsC}$ & -7.880 & \multicolumn{2}{|c|}{$<0.001$} & \multicolumn{2}{|c|}{0.905} \\
\hline mEsC & -8.585 & \multicolumn{2}{|c|}{$<0.001$} & \multicolumn{2}{|c|}{0.921} \\
\hline \multicolumn{6}{|l|}{ Healthcare workers } \\
\hline $\mathrm{mMC}$ & -1.040 & \multicolumn{2}{|c|}{0.298} & \multicolumn{2}{|c|}{-0.233} \\
\hline MHsC & -5.477 & \multicolumn{2}{|c|}{$<0.001$} & \multicolumn{2}{|c|}{0.907} \\
\hline MEsC & -6.042 & \multicolumn{2}{|c|}{$<0.001$} & \multicolumn{2}{|c|}{0.910} \\
\hline \multicolumn{6}{|c|}{ Non-Healthcare workers } \\
\hline $\mathrm{mMC}$ & -3.699 & \multicolumn{2}{|c|}{$<0.001$} & \multicolumn{2}{|c|}{-0.830} \\
\hline $\mathrm{mHsC}$ & -5.666 & \multicolumn{2}{|c|}{$<0.001$} & \multicolumn{2}{|c|}{0.898} \\
\hline mEsC & -6.139 & \multicolumn{2}{|c|}{$<0.001$} & \multicolumn{2}{|c|}{0.932} \\
\hline \multicolumn{6}{|c|}{ B. Differences in risk aptitudes } \\
\hline & $\begin{array}{l}\text { Healthcare Workers } \\
\quad(\text { mean } \pm S D)\end{array}$ & $\begin{array}{c}\text { Non-Healthcare } \\
\text { Workers } \\
\text { (mean } \pm S D \text { ) }\end{array}$ & $\mathbf{U}$ & p-value & $\mathbf{r}$ \\
\hline MC1 & $3.25( \pm 0.985)$ & $3.03( \pm 1.060)$ & 1880 & 0.242 & -0.110 \\
\hline MC2 & $3.25( \pm 0.943)$ & $3.45( \pm 0.867)$ & 2022.5 & 0.626 & 0.043 \\
\hline $\mathrm{mMC}$ & $3.28( \pm 0.910)$ & $3.23( \pm 0.965)$ & 2080.5 & 0.870 & -0.015 \\
\hline $\mathrm{HsC1}$ & $2.97( \pm 1.224)$ & $2.80( \pm 1.227)$ & 1943 & 0.401 & -0.080 \\
\hline $\mathrm{HsC2}$ & $1.51( \pm 1.017)$ & $1.34( \pm 0.796)$ & 1993.5 & 0.434 & -0.056 \\
\hline $\mathrm{mHsC}$ & $2.06( \pm 1.088)$ & $1.77( \pm 1.027)$ & 1795 & 0.108 & -0.150 \\
\hline
\end{tabular}




\begin{tabular}{|c|c|c|c|c|c|}
\hline EsC1 & $3.57( \pm 0.756)$ & $3.89( \pm 0.437)$ & 1562 & $<0.001$ & 0.261 \\
\hline EsC2 & $1.82( \pm 1.102)$ & $2.20( \pm 1.148)$ & 1704 & 0.040 & 0.193 \\
\hline mEsC & $2.642( \pm 1.007)$ & $3.154( \pm 0.854)$ & 1517.5 & 0.003 & 0.282 \\
\hline
\end{tabular}

$M C 1=$ monetary condition series $1, M C 2=$ monetary condition series $2, m M C=m e a n$ monetary condition, HsC1=health condition series 1 , HsC2= health condition series 2 , $\mathrm{mHsC}=$ mean health condition, EsC1= employment condition series 1, EsC2= employment condition series 2, $m E s C=m e a n$ employment condition, $z=$ Wilcoxon test, $r=$ rank-biserial correlation, $U=$ Mann Whitney, $S D=$ standard deviation 
Table 4 - Series 1 items of Lottery A and Lottery B for the three Covid-19 Risk Task conditions

\begin{tabular}{|c|c|c|c|}
\hline \multicolumn{4}{|c|}{ Covid-19 Risk Task Monetary Condition } \\
\hline $\begin{array}{l}\text { Decision } \\
\text { Raw }\end{array}$ & LOTTERY A & LOTTERY B & CRRA range \\
\hline 1 & $10 \% 200 €-90 \% 160 €$ & $10 \% 385 €-90 \% 10 €$ & $r<-0.95$ \\
\hline 2 & $20 \% 200 €-80 \% 160 €$ & $20 \% 385 €-80 \% 10 €$ & $-0.95<r>-0.49$ \\
\hline 3 & $30 \% 200 €-70 \% 160 €$ & $30 \% 385 €-70 \% 10 €$ & $-0.49<r>-0.15$ \\
\hline 4 & $40 \% 200 €-60 \% 160 €$ & $40 \% 385 €-60 \% 10 €$ & $-0.15<r>0.15$ \\
\hline 5 & $50 \% 200 €-50 \% 160 €$ & $50 \% 385 €-50 \% 10 €$ & $0.15<r>0.41$ \\
\hline 6 & $60 \% 200 €-40 \% 160 €$ & $60 \% 385 €-40 \% 10 €$ & $0.41<r>0.68$ \\
\hline 7 & $70 \% 200 €-30 \% 160 €$ & $70 \% 385 €-30 \% 10 €$ & $0.68<r>0.97$ \\
\hline 8 & $80 \% 200 €-20 \% 160 €$ & $80 \% 385 €-20 \% 10 €$ & $0.97<r>1.37$ \\
\hline 9 & $90 \% 200 €-10 \% 160 €$ & $90 \% 385 €-10 \% 10 €$ & $r>1.37$ \\
\hline 10 & $100 \% 200 €-0 \% 160 €$ & $100 \% 385 €-0 \% 10 €$ & $r>1.37$ \\
\hline \multicolumn{4}{|c|}{ Covid-19 Risk Task Health status Condition } \\
\hline $\begin{array}{l}\text { Decision } \\
\text { raw }\end{array}$ & LOTTERY A & LOTTERY B & CRRA \\
\hline 1 & $\begin{array}{c}10 \% \text { Symptomatic Covid-19 infection } \\
\text { without hospitalization - } 90 \% \text { Diabetes } \\
\text { Mellitus }\end{array}$ & $\begin{array}{l}\text { 10\% Shoulder Fracture - 90\% Symptomatic Covid-19 } \\
\text { infection with hospitalization }\end{array}$ & $r<-0.95$ \\
\hline 2 & $\begin{array}{c}20 \% \text { Symptomatic Covid-19 infection } \\
\text { without hospitalization }-80 \% \text { Diabetes } \\
\text { Mellitus }\end{array}$ & $\begin{array}{l}\text { 20\% Shoulder Fracture - 80\% Symptomatic Covid-19 } \\
\text { infection with hospitalization }\end{array}$ & $-0.95<r>-0.49$ \\
\hline 3 & $\begin{array}{c}30 \% \text { Symptomatic Covid-19 infection } \\
\text { without hospitalization - } 70 \% \text { Diabetes } \\
\text { Mellitus }\end{array}$ & $\begin{array}{l}\text { 30\% Shoulder Fracture - 70\% Symptomatic Covid-19 } \\
\text { infection with hospitalization }\end{array}$ & $-0.49<r>-0.15$ \\
\hline 4 & $40 \%$ Symptomatic Covid-19 infection & $40 \%$ Shoulder Fracture - 60\% Symptomatic Covid-19 & $-0.15<r>0.15$ \\
\hline
\end{tabular}




\begin{tabular}{|c|c|c|c|}
\hline & $\begin{array}{l}\text { without hospitalization }-60 \% \text { Diabetes } \\
\text { Mellitus }\end{array}$ & infection with hospitalization & \\
\hline 5 & $\begin{array}{c}50 \% \text { Symptomatic Covid-19 infection } \\
\text { without hospitalization - } 50 \% \text { Diabetes } \\
\text { Mellitus }\end{array}$ & $\begin{array}{l}50 \% \text { Shoulder Fracture - 50\% Symptomatic Covid-19 } \\
\text { infection with hospitalization }\end{array}$ & $0.15<r>0.41$ \\
\hline 6 & $\begin{array}{c}60 \% \text { Symptomatic Covid-19 infection } \\
\text { without hospitalization }-40 \% \text { Diabetes } \\
\text { Mellitus }\end{array}$ & $\begin{array}{l}\text { 60\% Shoulder Fracture - 40\% Symptomatic Covid-19 } \\
\text { infection with hospitalization }\end{array}$ & $0.41<r>0.68$ \\
\hline 7 & $\begin{array}{c}70 \% \text { Symptomatic Covid-19 infection } \\
\text { without hospitalization }-30 \% \text { Diabetes } \\
\text { Mellitus }\end{array}$ & $\begin{array}{l}\text { 70\% Shoulder Fracture - 50\% Symptomatic Covid-19 } \\
\text { infection with hospitalization }\end{array}$ & $0.68<r>0.97$ \\
\hline 8 & $\begin{array}{c}80 \% \text { Symptomatic Covid-19 infection } \\
\text { without hospitalization - } 20 \% \text { Diabetes } \\
\text { Mellitus }\end{array}$ & $\begin{array}{l}80 \% \text { Shoulder Fracture - 20\% Symptomatic Covid-19 } \\
\text { infection with hospitalization }\end{array}$ & $0.97<r>1.37$ \\
\hline 9 & $\begin{array}{c}90 \% \text { Symptomatic Covid-19 infection } \\
\text { without hospitalization }-10 \% \text { Diabetes } \\
\text { Mellitus }\end{array}$ & $\begin{array}{l}\text { 90\% Shoulder Fracture - 10\% Symptomatic Covid-19 } \\
\text { infection with hospitalization }\end{array}$ & $r>1.37$ \\
\hline 10 & $\begin{array}{c}100 \% \text { Symptomatic Covid-19 infection } \\
\text { without hospitalization - 0\% Diabetes } \\
\text { Mellitus }\end{array}$ & $\begin{array}{l}\text { 100\% Shoulder Fracture - 0\% Symptomatic Covid-19 } \\
\text { infection with hospitalization }\end{array}$ & $r>1.37$ \\
\hline \multicolumn{4}{|c|}{ Covid-19 Risk Task Employment status Condition } \\
\hline $\begin{array}{l}\text { Decision } \\
\text { Raw }\end{array}$ & Lottery A & Lottery B & CRRA \\
\hline 1 & $\begin{array}{c}10 \% \text { Paid Leave (salary reduced of } 2 / 3 \text { ) - } \\
90 \% \text { Work from home with } 50 \% \text { salary } \\
\text { reduction }\end{array}$ & $\begin{array}{c}10 \% 30 \text { days of paid leave }-90 \% \\
\text { Unpaid furlough }\end{array}$ & $r<-0.95$ \\
\hline 2 & $\begin{array}{l}20 \% \text { Paid Leave (salary reduced of } 2 / 3 \text { ) - } \\
80 \% \text { Work from home with } 50 \% \text { salary } \\
\text { reduction }\end{array}$ & $\begin{array}{c}20 \% 30 \text { days of paid leave }-80 \% \\
\text { Unpaid furlough }\end{array}$ & $-0.95<r>-0.49$ \\
\hline 3 & $\begin{array}{l}30 \% \text { Paid Leave (salary reduced of } 2 / 3 \text { ) - } \\
70 \% \text { Work from home with } 50 \% \text { salary }\end{array}$ & $\begin{array}{c}30 \% 30 \text { days of paid leave }-70 \% \\
\text { Unpaid furlough }\end{array}$ & $-0.49<r>-0.15$ \\
\hline
\end{tabular}




\begin{tabular}{|c|c|c|c|}
\hline & reduction & & \\
\hline 4 & $\begin{array}{l}40 \% \text { Paid Leave (salary reduced of } 2 / 3 \text { ) - } \\
60 \% \text { Work from home with } 50 \% \text { salary } \\
\text { reduction }\end{array}$ & $\begin{array}{c}40 \% 30 \text { days of paid leave }-60 \% \\
\text { Unpaid furlough }\end{array}$ & $-0.15<r>0.15$ \\
\hline 5 & $\begin{array}{l}50 \% \text { Paid Leave (salary reduced of } 2 / 3 \text { ) - } \\
50 \% \text { Work from home with } 50 \% \text { salary } \\
\text { reduction }\end{array}$ & $\begin{array}{c}50 \% 30 \text { days of paid leave }-50 \% \\
\text { Unpaid furlough }\end{array}$ & $0.15<r>0.41$ \\
\hline 6 & $\begin{array}{l}60 \% \text { Paid Leave (salary reduced of } 2 / 3 \text { ) - } \\
40 \% \text { Work from home with } 50 \% \text { salary } \\
\text { reduction }\end{array}$ & $\begin{array}{c}60 \% 30 \text { days of paid leave }-40 \% \\
\text { Unpaid furlough }\end{array}$ & $0.41<r>0.68$ \\
\hline 7 & $\begin{array}{l}\text { 70\% Paid Leave (salary reduced of } 2 / 3 \text { ) - } \\
30 \% \text { Work from home with } 50 \% \text { salary } \\
\text { reduction }\end{array}$ & $\begin{array}{c}70 \% 30 \text { days of paid leave }-30 \% \\
\text { Unpaid furlough }\end{array}$ & $0.68<r>0.97$ \\
\hline 8 & $\begin{array}{l}80 \% \text { Paid Leave (salary reduced of } 2 / 3 \text { ) - } \\
20 \% \text { Work from home with } 50 \% \text { salary } \\
\text { reduction }\end{array}$ & $\begin{array}{c}80 \% 30 \text { days of paid leave }-20 \% \\
\text { Unpaid furlough }\end{array}$ & $0.97<r>1.37$ \\
\hline 9 & $\begin{array}{l}90 \% \text { Paid Leave (salary reduced of } 2 / 3 \text { ) - } \\
10 \% \text { Work from home with } 50 \% \text { salary } \\
\text { reduction }\end{array}$ & $\begin{array}{c}90 \% 30 \text { days of paid leave }-10 \% \\
\text { Unpaid furlough }\end{array}$ & $r>1.37$ \\
\hline 10 & $\begin{array}{c}100 \% \text { Paid Leave (salary reduced of } 2 / 3 \text { ) - } \\
0 \% \text { Work from home with } 50 \% \text { salary } \\
\text { reduction }\end{array}$ & $\begin{array}{c}100 \% 30 \text { days of paid leave }-0 \% \\
\text { Unpaid furlough }\end{array}$ & $r>1.37$ \\
\hline
\end{tabular}


$\frac{5 \overline{5}}{\frac{10}{50}}$ 


$$
=
$$


Supplementary Table $\mathbf{S 1}$ - List of items used to create the Health status Condition ( $\mathrm{HsC}$ ) of the Covid-19 Risk Task and relative rating scores

\begin{tabular}{|c|c|c|}
\hline Severity perception & $\begin{array}{c}\text { HsC item options } \\
\text { (pathological condition) }\end{array}$ & $\begin{array}{c}\text { Rating } \\
\text { (average } \\
\text { data) }\end{array}$ \\
\hline $\begin{array}{c}1 \\
\text { (less severe } \\
\text { condition) }\end{array}$ & Cold & 1.21 \\
\hline 2 & Sore throat & 1.50 \\
\hline 3 & Cough & 1.71 \\
\hline 4 & Diarrhea & 1.76 \\
\hline 5 & Hemorrhoids & 1.76 \\
\hline 6 & Headache & 1.92 \\
\hline 7 & Gastroesophageal reflux & 2.08 \\
\hline 8 & Cystitis & 2.13 \\
\hline 9 & Allergy & 2.21 \\
\hline 10 & Psoriasis & 2.24 \\
\hline 11 & Shoulder fracture & 2.42 \\
\hline 12 & Asymptomatic Covid-19 infection & 2.63 \\
\hline 13 & Arthrosis & 2.82 \\
\hline 14 & Bronchial asthma & 2.84 \\
\hline 15 & Osteoporosis & 2.95 \\
\hline 16 & Thighbone fracture & 3 \\
\hline 17 & $\begin{array}{c}\text { Symptomatic Covid-19 infection without } \\
\text { hospitalization }\end{array}$ & 3 \\
\hline 18 & Diabetes mellitus & 3.53 \\
\hline 19 & Symptomatic Covid-19 infection with hospitalization & 4.05 \\
\hline 20 & AIDS & 4.37 \\
\hline 21 & Alzheimer's disease & 4.37 \\
\hline 22 & Lung cancer & 4.45 \\
\hline 23 & Heart attack & 4.47 \\
\hline $\begin{array}{c}24 \\
\text { (most severe } \\
\text { condition) }\end{array}$ & Stroke & 4.53 \\
\hline
\end{tabular}


Supplementary Table S2 - List of items used to create the Health status Condition (HsC) of the Covid-19 Risk Task and relative rating scores.

\begin{tabular}{|c|c|c|}
\hline $\begin{array}{l}\text { Severity } \\
\text { perception }\end{array}$ & EsC item options (employment status) & $\begin{array}{c}\text { Rating } \\
\text { (average } \\
\text { data) }\end{array}$ \\
\hline $\begin{array}{c}1 \\
\text { (less severe } \\
\text { condition) }\end{array}$ & Work from home with full salary & 1.31 \\
\hline 2 & Paid leave (full salary) & 1.71 \\
\hline 3 & Work with paid overtime & 1.94 \\
\hline 4 & 5 days of paid leave & 2 \\
\hline 5 & $\begin{array}{l}\text { Work full salary }+ \text { bonus from government support } \\
\text { (DPCM-Curaltalia) }\end{array}$ & 2 \\
\hline 6 & Work with standard salary & 2.08 \\
\hline 7 & 15 days of paid leave & 2.16 \\
\hline 8 & $\begin{array}{l}\text { Freelance job (a third of income + bonus from } \\
\text { government support, DPCM-Curaltalia) }\end{array}$ & 2.16 \\
\hline 9 & 10 days of paid leave & 2.26 \\
\hline 10 & 15 sick-leave days & 2.29 \\
\hline 11 & 10 sick-leave days & 2.34 \\
\hline 12 & Work without meal voucher & 2.37 \\
\hline 13 & Work with reduced work hours (part-time) & 2.58 \\
\hline 14 & 30 sick-leave days & 2.63 \\
\hline 15 & 30 days of paid leave & 2.66 \\
\hline 16 & Paid leave (salary reduced $50 \%$ ) & 2.66 \\
\hline 17 & Paid leave (salary reduced of $2 / 3$ ) & 2.92 \\
\hline 18 & "Cassa Integrazione" (paid furlough) & 3.08 \\
\hline 19 & Work from home with $50 \%$ salary reduction & 3.18 \\
\hline 20 & Work with unpaid overtime & 3.29 \\
\hline 21 & Unpaid furlough & 3.74 \\
\hline 22 & $\begin{array}{l}\text { Freelance with reduced work hours ( } 2 / 3 \text { reduction) } \\
\text { with no government support }\end{array}$ & 3.92 \\
\hline 23 & Unpaid work from home & 4.26 \\
\hline $\begin{array}{c}24 \\
\text { (most severe } \\
\text { condition) }\end{array}$ & Layoff & 4.39 \\
\hline
\end{tabular}

